\title{
Social Determinants of Hookah Smoking in the United States
}

\author{
Shervin Assari ${ }^{*}$, Hamid Chalian ${ }^{2}$, Mohsen Bazargan ${ }^{1,3}$ \\ Department of Family Medicine, Charles R Drew University of Medicine and Science, Los Angeles, CA \\ ${ }^{2}$ Department of Radiology, Department of Radiology, Duke University Medical Center, Durham, USA \\ ${ }^{3}$ Department of Family Medicine, University of California Los Angeles, Los Angeles, CA 90095, USA
}

Article Info

\section{Article Notes}

Received: December 19, 2019

Accepted: January 17, 2020

\section{*Correspondence:}

Dr. Shervin Assari, MD MPH, Department of Family Medicine, Charles R Drew University of Medicine and Science, Los Angeles, CA, USA; Email: assari@umich.edu.

C 2020 Assari S. This article is distributed under the terms of the Creative Commons Attribution 4.0 International License.

\section{Keywords:}

Population groups

Race

Hispanics

Ethnicity

Latinos

Whites

Blacks

African Americans

Socioeconomic status

Socioeconomic position

Poverty status

Education

Smoking

Tobacco use

\section{Abstract}

Background: Educational attainment and income are two socioeconomic status indicators with strong protective effects against cigarette smoking. Marginalization-related Diminished Returns, however, refer to less than expected protective effects of socioeconomic status indicators for the members of the racial and ethnic minority groups, particularly Blacks and Hispanics, compared to non-Hispanic Whites.

Aim: Borrowing data from a nationally representative study in the US, this study tested whether racial and ethnic differences exist in the effects of educational attainment and poverty status on cigarette smoking of American adults.

Methods: This cross-sectional study entered 28,329 adult participants of the Population Assessment of Tobacco and Health (PATH; 2013). Both educational attainment and poverty status were the independent variables. The dependent variable was current hookah smoking. Age, gender, and region were the covariates. Race and ethnicity were the effect modifiers (moderators).

Results: Overall, individuals with higher educational attainment were more likely to smoke a hookah. Individuals who lived out of poverty, however, had lower odds of current hookah smoking. Race and ethnicity both showed statistical interactions with both socioeconomic indicators suggesting that Blacks and Hispanics with high educational attainment and those who live out of poverty have disproportionately high odds of hookah smoking, compared to non-Hispanic Whites with high socioeconomic status.

Conclusions: In the United States, middle-class racial and ethnic minority people remain at higher risk of smoking hookah. As a result, we should expect a high tobacco burden in middle-class Black and Hispanic adults. We suggest that policymakers should not take an over-simplistic way and reduce the problem of race/ethnic inequalities in tobacco use to gaps in socioeconomic status between groups. Marginalization-related diminished returns generate tobacco disparities in higher socioeconomic status levels. Middle-class racial and ethnic minority people need extra support to stay healthy.

\section{Introduction}

Despite the recent decline in the prevalence of tobacco use in the United States, cigarette smoking remains one of the top preventable causes of morbidity and mortality in this country ${ }^{1-3}$. Each year, about 480,000 Americans die from illnesses that are due to tobacco use. In addition, more than 16 million Americans suffer from diseases that are caused by smoking ${ }^{4}$. As a result, tobacco costs the United States more than $\$ 300$ billion each year, which is composed of $\$ 170$ and $\$ 156$ billion for direct and indirect costs, respectively ${ }^{5}$. 
The burden of tobacco use, however, is not randomly distributed in the United States ${ }^{6-10}$. Despite the enormous progress that has been achieved in reducing the overall tobacco-related morbidity and mortality, cigarette smoking has transformed from a health challenge that impacts mainstream populations to a public health challenge that is highly concentrated in the marginalized populations defined by socioeconomic status, race, ethnicity, and sexual orientation ${ }^{11}$. Such social inequalities diminish the achievements of the United States regarding tobacco control ${ }^{11}$.

Racial and ethnic minorities ${ }^{6-10}$ and low socioeconomic status individuals ${ }^{12-14}$ bear the vast majority of tobacco burden in the US. Some evidence suggests that the socioeconomic status disparities in tobacco use have increased $^{14-16}$. From 1966 to 2015, cigarette smoking declined by $83 \%$ in American adults with a college degree. At the same time, the decline was only $40 \%$ for Americans who did not have a high school diploma ${ }^{11}$. A large proportion of tobacco disparities may not be due to choices of the individuals but large scale upstream societal processes that place marginalized groups at higher risk of exposure to tobacco. For example, racial, ethnic, and low socioeconomic status individuals are the target of predatory tobacco marketing ${ }^{17-19}$. In a recent study, nonHispanic Whites with high education remembered the fewest number of tobacco ads ${ }^{20}$. Black and Hispanic people with high education, however, reported a high number of tobacco $\operatorname{ads}^{20}$. This finding suggested that tobacco marketing may have a role in explaining why middle-class Hispanic and Black individuals remain at risk of tobacco $u^{20} e^{20}$. Low socioeconomic status individuals, as well as racial and ethnic minorities, are more frequently exposed to a wide range of environmental tobacco risk factors such as advertisements, retail displays, coupons, and discounts ${ }^{21}$. The result is their increasing vulnerability of racial/ethnic and low socioeconomic status individuals ${ }^{22}$, which is characterized by a more rapid transition from initiation to undesired outcomes, in part due to low access to cessation programs $s^{8,23,24}$.

Marginalization - related Diminished Returns (MDRs) ${ }^{25,26}$ refer to "weaker than expected" protective effects of socioeconomic indicators, particularly educational attainment on a wide range of health outcomes including but not limited to tobacco use for minority compared to the majority populations ${ }^{27-29}$. According to the MDRs, at least some of the racial/ethnic disparities in health are due to diminishing returns of educational attainment and other socioeconomic resources on securing tangible outcomes for the members of socially marginalized compared to socially privileged groups. This model proposes that: (a) racial/ethnic inequalities in tobacco burden are not all due to socioeconomic gaps, but at least some of it is due to smaller effects of socioeconomic indicators for minority populations, and (b) the racial and ethnic gap in tobacco use widens as socioeconomic status increases. This model emphasizes a need to study racial/ethnic tobacco disparities across all socioeconomic status levels and suggests that the solution to tobacco disparities is beyond equalizing socioeconomic status ${ }^{27-29}$. There is a need to study if diminished returns are causing racial and ethnic disparities for various tobacco products in the US ${ }^{27-29}$. Previously, such diminished returns were described for tobacco use, tobacco dependence ${ }^{30}$, smoking ${ }^{29}$, vaping ${ }^{31}$, and even alcohol use $\mathrm{e}^{28,32}$.

While minorities' diminished returns of education on tobacco, e-cig, tobacco dependence, and even alcohol use, and alcohol binge drinking are shown, these patterns are not shown for other types of substances. While similar to any other country, there are many types of tobacco available in America, these substances and methods of use may have different predictors. They may also be differently influenced by social determinants of health, such as socioeconomic status. Thus, there is a need to test if similar diminished returns also apply to other forms of use. From various tobacco products, hookah has received one of the least amounts of attention by researchers. Thus, there is a need for additional studies on hookah smoking, a method of use with very limited existing knowledge.

This study tested race/ethnic variation in the effects of two socioeconomic status indicators, namely educational attainment and poverty status, on hookah smoking in a nationally representative sample of American adults. We expected smaller protective effects of educational attainment and living out of poverty on hookah use for Black and Hispanic than Non-Hispanic White Americans. As marginalization-related diminished returns are not because of groups' or individuals' characteristics but the marginalization of racial and minority populations ${ }^{25,26}$, we expected similar diminished returns for Blacks and Hispanics.

\section{Methods}

\section{Design and settings}

We conducted a cross-sectional study. The source of data for the current secondary analysis came from wave 1 of the Population Assessment of Tobacco and Health (PATH) -Adults. PATH is funded by the National Institute for Health and the Food and Drug Administration and generates valid nationally representative prevalence estimates on tobacco use in the US population. Data collection was conducted in 2013-2014.

\section{Data retrieval}

We used Wave1 of the PATH data for this analysis. Data were downloaded from the University of Michigan Inter- 
university Consortium for Political and Social Research. We merged data sets DS0001 and DS1001 for the purpose of this study, using the identifiers in the Master Linkage file. The former is a Master Linkage file and includes 53,178 youth and adults. The later includes 32,320 adults (Wave 1 Adult Questionnaire). This study only includes 28,329 adults. All the data for this proposal is at the individual level.

\section{Sample \& sampling}

The PATH sample is composed of non-institutionalized, civilian, American adults. The PATH study used a four-stage stratified and clustered probability sample that introduces the survey weights and nested data.

\section{Analytical sample}

The current analysis was limited to all adults aged 18 or more who had data on our variables (see below for a list). While the original sample size was 32,320 adults, this study includes only 25,654 adults. Individuals who were not included in the current analysis were either from other races and ethnic groups or did not have a valid measure on their study variables.

\section{Study variables}

Variables in this analysis included race, ethnicity, socioeconomic status indicators (poverty status and educational attainment), hookah use, and demographic indicators (age and gender), all measured at the individual level.

Moderator: Race and ethnicity were self-identified in this study. These variables were treated as two dichotomous variables: Race (Non-Hispanic Blacks versus Non-Hispanic Whites) and Ethnicity (Hispanics versus Non-Hispanics).

Independent Variables (socioeconomic indicators): Educational attainment was a six-level variable as below: 1) Less than High School, 2) General Educational Development, 3) High school graduate, 4) Some college (no degree) or associate degree, 5) Bachelor's degree, and 6) Advanced degree. Poverty status was dichotomous variable 0) below $100 \%$ federal poverty line, 1) above $100 \%$ federal poverty line.

Dependent Variable: The outcome was the current smoking of hookah, which was self-reported. Current hookah smoking was defined as hookah smoked daily or sometimes in the past 30 days.

Confounders: Age was a continuous measure, ranging from 1 to 7 as below: 1) 18 to 24 years old, 2) 25 to 34 years old, 3) 35 to 44 years old, 4) 45 to 54 years old, 5) 55 to 64 years old, 6) 65 to 74 years old, and 7) 75 years old or older. Gender was a dichotomous variable with females as the reference group.

\section{Statistics}

To analyze the PATH-Adults data, we used SPSS 23.0 (IBM Corporation, Armonk, NY, USA). To apply the weights, which was necessary to produce results that were generalizable to the US general population, we re-estimated the variance and standard errors using Taylor series linearization. Thus, our analyses addressed the survey design due to sample weight, PSU, clustering, and stratification. For data analysis, first, we tested whether there is any collinearity between race, ethnicity, educational attainment, and poverty status. We did not find any evidence suggesting any collinearity. We ran two logistic regression models in the overall sample; first, a model without (Model 1) and second, a model with (Model 2) four interaction terms between race, ethnicity, educational attainment, and poverty status.

\section{Ethics}

All the participants provided written informed consent. The Institutional Review Board of the Westat approved the PATH study protocol.

\section{Results}

\section{Descriptive statistics}

This study included 25,654 American adults who were either Non-Hispanic White (68.0\%), Non-Hispanic Black (15.9\%), or Hispanic White (14.9\%), or Hispanic Black (1.3\%). Table 1 shows descriptive statistics of the overall sample. Participants were almost half men and women.

\section{Multivariable models}

Table 2 shows a summary of the output of two logistic regression models. In these models, educational attainment and poverty status were the independent variables, and smoking hookah was the dependent variable. Both models were estimated in the total sample, which included Whites, Blacks, Hispanics, and non-Hispanics. Model 1 only entered the main effects of socioeconomic status indicators (educational attainment and poverty status) as well as race, ethnicity, and covariates. Model 2, however, also added four statistical interaction terms between race and ethnicity with education and poverty status.

Based on Model 1, Blacks (OR = 1.17; 95\% CI =1.04 1.32 ) and Hispanics $(\mathrm{OR}=1.32 ; 95 \% \mathrm{CI}=1.18-1.48)$ were more likely than Whites and non-Hispanics to use hookah. There was a positive association between education and hookah smoking (OR $=1.11 ; 95 \% \mathrm{CI}=1.06-1.15)$. This model also showed a protective effect of income (living out of poverty) on hookah smoking. Other factors that were associated with hookah use included lesbian, gay, bisexual, and transgender status $(\mathrm{OR}=1.79 ; 95 \% \mathrm{CI}=1.55-2.07)$, male gender $(\mathrm{OR}=1.37 ; 95 \% \mathrm{CI}=1.25-1.51)$, and age $(\mathrm{OR}$ $=0.39 ; 95 \% \mathrm{CI}=0.37-0.41$ ). 
Table 1. Descriptive statistics.

\begin{tabular}{|l|c|c|}
\hline & $\mathbf{n}$ & $\%$ \\
\hline Race & & \\
\hline Black & 4874 & 17.1 \\
\hline White & 23625 & 82.9 \\
\hline Ethnicity & & \\
\hline Hispanic & 4647 & 16.3 \\
\hline Non-Hispanic & 23852 & 83.7 \\
\hline Gender & & \\
\hline Women & 14199 & 49.8 \\
\hline Men & 14300 & 50.2 \\
\hline Lesbian, Gay, Bisexual & & \\
\hline No & 25992 & 93.3 \\
\hline Yes & 1868 & 6.7 \\
\hline Age & & \\
\hline $1=18$ to 24 years old & 7730 & 27.3 \\
\hline $2=25$ to 34 years old & 5524 & 19.5 \\
\hline $3=35$ to 44 years old & 4330 & 15.3 \\
\hline $4=45$ to 54 years old & 4322 & 15.3 \\
\hline $5=55$ to 64 years old & 3561 & 12.6 \\
\hline $6=65$ to 74 years old & 1948 & 6.9 \\
\hline $7=75$ years old or older & 910 & 3.2 \\
\hline Education & & \\
\hline $1=$ Less than high school & 3635 & 12.8 \\
\hline $2=$ General education development & 1953 & 6.9 \\
\hline $3=$ High school graduate & 6695 & 23.6 \\
\hline $4=$ Some college (no degree) or associates degree & 10068 & 35.5 \\
\hline $5=$ Bachelor's degree & 3954 & 14.0 \\
\hline $6=$ Advanced degree & 2024 & 7.1 \\
\hline Poverty Status & 2537 & 8.9 \\
\hline Living in poverty & 17212 & 66.9 \\
\hline Living out of poverty & 91.1 \\
\hline Current Hookah & & \\
\hline Non-Smoker & & \\
\hline Smoker & & \\
\hline
\end{tabular}

Model 2 suggested that significant interactions exist between the effects of race and ethnicity with education and poverty status on hookah smoking, suggesting that high education and living out of poverty both have smaller inverse associations with smoking of hookah for Blacks and Hispanics than non-Hispanics and Whites. This was evident by the ORs smaller than 1 for the main effects of socioeconomic resources and ORs larger than 1 for the interaction terms between race and ethnicity with socioeconomic resources. Interactions were significant for education and race $(\mathrm{OR}=1.31 ; 95 \% \mathrm{CI}=1.18-1.46)$, education and ethnicity (OR $=1.12 ; 95 \% \mathrm{CI}=1.02-1.22)$, income [living out of poverty] and race $(\mathrm{OR}=1.36 ; 95 \% \mathrm{CI}=$ $1.06-1.74$ ) and income [living out of poverty] and ethnicity $(\mathrm{OR}=1.52 ; 95 \% \mathrm{CI}=1.21$ - 1.92) (Table 2).

\section{Discussion}

The current study showed that while education and poverty status are associated with higher odds of hookah smoking, these associations differ based on race and ethnicity. Race and ethnicity seem to interact with both socioeconomic indicators suggesting that middle-class Blacks and Hispanics are at disproportionately high risk of smoking hookah.

Our MDRs work shows that middle-class Blacks and Hispanics remain at a disproportionately high risk of substance use compared to their White counterparts ${ }^{28,29,32,33}$. A similar pattern is shown for almost every socioeconomic indicator and health outcome ${ }^{25,26}$. For example, the magnitude of the effects of education ${ }^{34}$, income ${ }^{35}$, marital status $^{36}$, and employment status ${ }^{37}$ on diet ${ }^{38}$, exercise ${ }^{39}$, depression ${ }^{40}$, anxiety ${ }^{36}$ and self-rated health ${ }^{34,41}$ are smaller for Hispanic and Black compared to non-Hispanic White people. Similar patterns are shown for physical health outcomes such as obesity ${ }^{42}$, hypertension ${ }^{43}$, attention deficit

Table 2. Logistic regressions on current hookah smoking models in the pooled sample.

\begin{tabular}{|l|c|c|c|c|c|c|}
\hline & \multicolumn{3}{|c|}{$\begin{array}{c}\text { Model 1 } \\
\text { Main Effects }\end{array}$} & \multicolumn{3}{c|}{ Model 1 + Interactions } \\
\hline & OR & $\mathbf{9 5 \%}$ Cl & p & OR & $95 \%$ Cl & p \\
\hline Race (Blacks) & 1.17 & $1.04-1.32$ & 0.009 & 0.39 & $0.27-0.56$ & $<0.001$ \\
\hline Ethnicity (Hispanics) & 1.32 & $1.18-1.48$ & $<0.001$ & 0.73 & $0.53-1.00$ & 0.051 \\
\hline Lesbian, Gay, Bisexual, and Transgender & 1.79 & $1.55-2.07$ & $<0.001$ & 1.82 & $1.57-2.09$ & $<0.001$ \\
\hline Gender (Men) & 1.37 & $1.25-1.51<0.001$ & 1.38 & $1.26-1.52$ & $<0.001$ \\
\hline Age (1-7) & 0.39 & $0.37-0.41$ & $<0.001$ & 0.39 & $0.37-0.41$ & $<0.001$ \\
\hline Educational Attainment (1-6) & 1.11 & $1.06-1.15$ & $<0.001$ & 1.03 & $0.98-1.08$ & 0.272 \\
\hline Living Out of Poverty & 0.87 & $0.79-0.97$ & 0.008 & 0.74 & $0.65-0.84$ & $<0.001$ \\
\hline Educational Attainment (1-6) x Race (Blacks) & & & & 1.31 & $1.18-1.46$ & $<0.001$ \\
\hline Educational Attainment (1-6) x Ethnicity (Hispanics) & & & & 1.12 & $1.02-1.22$ & 0.023 \\
\hline Living Out of Poverty $x$ Race (Blacks) & & & & 1.36 & $1.06-1.74$ & 0.014 \\
\hline Living Out of Poverty $x$ Ethnicity (Hispanics) & & & & 1.52 & $1.21-1.92$ & $<0.001$ \\
\hline Intercept & 0.41 & & $<0.001$ & 0.58 & $<0.001$ \\
\hline
\end{tabular}

$\mathrm{Cl}$ : Confidence Interval;

SE: Standard Error;

OR: Odds Ratio;

Outcome: Current hookah smoking. 
hyperactivity disorder ${ }^{44}$, chronic obstructive pulmonary disease $^{45}$, disability ${ }^{46}$, and chronic disease ${ }^{44}$ are all smaller for Hispanic and Black than White people.

There is a need to understand the role of predatory marketing practices on racial/ethnic and socioeconomic status disparities in tobacco use. We argue that predatory marketing and advertising may be at least in part responsible for the disproportionately high risk of tobacco use among middle-class Black and Hispanic individuals, relative to middle-class Whites. At least some evidence suggests that minority and vulnerable populations are targets of aggressive tobacco marketing ${ }^{47-49}$. In a recent study, highly educated Blacks and Hispanics reported more tobacco ads, while highly educated Whites reported fewest tobacco ads ${ }^{20}$. Although more research is needed, if such a hypothesis is supported, then introducing more restrictive and tight marketing policies that do not allow point-of-sale advertisement and flavoring, particularly in areas where ethnic minorities live, may reduce the racial and ethnic disparities that are due to MDRs. Such strategies may disproportionately impact Black and Hispanic populations. In other words, restricting predatory marketing may contribute to the elimination of tobacco use disparities by race, ethnicity, and socioeconomic status; however, this hypothesis needs more research ${ }^{50}$.

\section{Implications}

Policies are needed at a national as well as local levels that can reduce the racial/ethnic and socioeconomic disparities in tobacco use, and reducing MDRs of socioeconomic status are among them ${ }^{26,28,29,33-36,42,51,52}$. Banning discounts, coupons, and flavoring in communities of color may reduce the increasing tobacco use of middle-class Blacks and Hispanics ${ }^{28,29}$. It is also unknown how tobacco regulations can reduce the MDRs-related disparities in tobacco use, particularly higher than expected tobacco use of middleclass Black and Hispanic people ${ }^{28,29,32,33}$. We still do not know how marketing strategies disproportionately impact communities of color. To undo racial and ethnic disparities in tobacco use, there might be a need to ban predatory marketing that may be ongoing in the communities of color.

\section{Limitations}

This study has a few methodological limitations. All cross-sectional studies are limited in drawing causal inferences. Thus, our results only suggest association rather than causation. The sample size was smaller for racial and ethnic minority groups. Income, employment, marital status, and area-level socioeconomic status were not a part of this study. Other tobacco products and other ethnic groups were also not included. This study did not measure health. Despite the limitations that were listed, this study still made a unique contribution to the literature.

\section{Conclusion}

In the United States, race and ethnic minority status limit the amount of health gain that usually follows the availability of socioeconomic status indicators such as education and income. While socioeconomic status resources help people avoid behaviors such as smoking hookah, racial and ethnic majority groups gain the most, and racial and ethnic minorities gain the least from their available resources. In the same line, we observe an additional risk of hookah smoking in middle-class Blacks and Hispanics. Policymakers should not reduce the problem of health disparities to low socioeconomic status but also societal mechanisms that reduce the marginal returns of socioeconomic resources. Thus, inequalities remain across all socioeconomic status levels. Policymakers should be aware that health disparities also affect middle-class Blacks and Hispanics, which is one of the major growing sections of the US population.

\section{Funding}

The research reported in this publication was supported by the National Cancer Institute of the National Institutes of Health and Food and Drug Administration Center for Tobacco Products under Award Number U54CA229974. The content is solely the responsibility of the authors and does not necessarily represent the official views of the National Institutes of Health or the Food and Drug Administration. Shervin Assari is also funded by the National Institutes of Health awards U54MD008149, R25 MD007610, U54MD007598, U54 TR001627, CA20141502 and 5S21MD000103.

\section{Conflicts of Interest}

The authors declare no conflict of interest.

\section{Author Contributions}

S.A. conceptualized the study, analyzed the data, prepared the first draft of the paper, and acquired the funding. M.B. and H.C. contributed to the revision and conceptualization of the study. All authors approved the final draft.

\section{References}

1. McCarthy M. Smoking remains leading cause of premature death in US. BMJ. 2014; 348: g396.

2. Samet JM. Tobacco smoking: the leading cause of preventable disease worldwide. Thorac Surg Clin. 2013; 23(2): 103-112.

3. Novick LF. Smoking is the leading preventable cause of death and disability in the United States. J Public Health Manag Pract. 2000; 6(3): vi.

4. CDC. Smoking \& Tobacco Use. Fast Facts. 2019.

5. CDC. Economic Trends in Tobacco.

6. Ellickson PL, Orlando M, Tucker JS, et al. From adolescence to young adulthood: racial/ethnic disparities in smoking. Am J Public Health. 2004; 94(2): 293-299. 
7. Centers for Disease C, Prevention. Racial disparities in smokingattributable mortality and years of potential life lost --- Missouri, 2003-2007. MMWR Morb Mortal Wkly Rep. 2010; 59(46): 1518-1522.

8. Trinidad DR, Perez-Stable EJ, White MM, et al. A nationwide analysis of US racial/ethnic disparities in smoking behaviors, smoking cessation, and cessation-related factors. Am J Public Health. 2011; 101(4): 699706.

9. Soulakova JN, Huang H, Crockett LJ. Racial/Ethnic Disparities in Consistent Reporting of Smoking-Related Behaviors. J Addict Behav Ther Rehabil. 2015; 4(4).

10. Blumenthal DS. Racial and ethnic disparities in smoking prevalence in Israel and the United States: progress to date and prospects for the future. Isr J Health Policy Res. 2017; 6(1): 51.

11. Drope J, Liber AC, Cahn Z, et al. Who's still smoking? Disparities in adult cigarette smoking prevalence in the United States. CA Cancer J Clin. 2018; 68(2): 106-115.

12. Laveist TA, Thorpe RJ, Jr, Mance GA, et al. Overcoming confounding of race with socio-economic status and segregation to explore race disparities in smoking. Addiction. 2007; 102 Suppl 2: 65-70.

13. Reid JL, Hammond D, Driezen P. Socio-economic status and smoking in Canada, 1999-2006: has there been any progress on disparities in tobacco use? Can J Public Health. 2010; 101(1): 73-78.

14. Zhang X, Martinez-Donate AP, Jones NR. Educational disparities in home smoking bans among households with underage children in the United States: can tobacco control policies help to narrow the gap? Nicotine Tob Res. 2013; 15(12): 1978-1987.

15. Reimer RA, Gerrard M, Gibbons FX. Racial disparities in smoking knowledge among current smokers: data from the health information national trends surveys. Psychol Health. 2010; 25(8): 943-959.

16. Rock VJ, Davis SP, Thorne SL, et al. Menthol cigarette use among racial and ethnic groups in the United States, 2004-2008. Nicotine Tob Res. 2010; 12 Suppl 2: S117-124.

17. Terry-McElrath YM, Wakefield MA, Emery S, et al. State anti-tobacco advertising and smoking outcomes by gender and race/ethnicity. Ethn Health. 2007; 12(4): 339-362.

18. Keeler C, Max W, Yerger V, et al. The Association of Menthol Cigarette Use With Quit Attempts, Successful Cessation, and Intention to Quit Across Racial/Ethnic Groups in the United States. Nicotine Tob Res. 2017; 19(12): 1450-1464.

19. Giovenco DP, Spillane TE, Merizier JM. Neighborhood differences in alternative tobacco product availability and advertising in New York City: Implications for health disparities. Nicotine Tob Res. 2018.

20. Assari S. Association of Educational Attainment and Race/Ethnicity With Exposure to Tobacco Advertisement Among US Young Adults. JAMA Netw Open. 2020; 3(1): e1919393.

21. Anderson SJ. Marketing of menthol cigarettes and consumer perceptions: a review of tobacco industry documents. Tob Control. 2011; 20 Suppl 2: ii20-28.

22. Greaves L, Hemsing N. Women and tobacco control policies: socialstructural and psychosocial contributions to vulnerability to tobacco use and exposure. Drug Alcohol Depend. 2009; 104 Suppl 1: S121130

23. Cokkinides VE, Halpern MT, Barbeau EM, et al. Racial and ethnic disparities in smoking-cessation interventions: analysis of the 2005 National Health Interview Survey. Am J Prev Med. 2008; 34(5): 404412 .

24. Tran ST, Rosenberg KD, Carlson NE. Racial/ethnic disparities in the receipt of smoking cessation interventions during prenatal care. Matern Child Health J. 2010; 14(6): 901-909.

25. Assari S. Health Disparities due to Diminished Return among Black
Americans: Public Policy Solutions. Social Issues and Policy Review. 2018; 12(1): 112-145.

26. Assari S. Unequal Gain of Equal Resources across Racial Groups. Int J Health Policy Manag. 2017; 7(1): 1-9.

27. Shervin A, Ritesh M. Diminished Return of Employment on Ever Smoking Among Hispanic Whites in Los Angeles. Health Equity. 2019; 3(1): 138-144.

28. Assari S, Farokhnia M, Mistry R. Education Attainment and Alcohol Binge Drinking: Diminished Returns of Hispanics in Los Angeles. Behav Sci Basel. 2019; 9(1).

29. Assari S, Mistry R. Educational Attainment and Smoking Status in a National Sample of American Adults; Evidence for the Blacks' Diminished Return. Int J Environ Res Public Health. 2018; 15(4).

30. Assari S, Caldwell CH, Bazargan M. Association Between Parental Educational Attainment and Youth Outcomes and Role of Race/ Ethnicity. JAMA Netw Open. 2019; 2(11): e1916018.

31. Assari S, Mistry R, Bazargan M. Race Educational Attainment and E-Cigarette Use. Journal of Medical Research and Innovation. 2020; 4(1): e000185-e000185.

32. Assari S, Lankarani MM. Education and Alcohol Consumption among Older Americans; Black-White Differences. Front Public Health. 2016; 4: 67 .

33. Assari S, Mistry R. Educational Attainment and Smoking Status in a National Sample of American Adults; Evidence for the Blacks Diminished Return. Int J Environ Res Public Health. 2018; 15(10).

34. Assari S. Blacks' Diminished Return of Education Attainment on Subjective Health Mediating Effect of Income. Brain Sci. 2018; 8(9).

35. Assari S, Hani N. Household Income and Children's Unmet Dental Care Need Blacks' Diminished Return. Dent J (Basel). 2018; 6(2).

36. Assari S, Caldwell CH, Zimmerman MA. Family Structure and Subsequent Anxiety Symptoms; Minorities' Diminished Return. Brain Sci. 2018; 8(6).

37. Assari S. Whites but Not Blacks Gain Life Expectancy from Social Contacts. Behav Sci (Basel). 2017; 7(4).

38. Assari S, Lankarani M. Educational Attainment Promotes Fruit and Vegetable Intake for Whites but Not Blacks. J. 2018; 1(1): 5.

39. Assari S. Educational Attainment and Exercise Frequency in American Women; Blacks' Diminished Returns. Women's Health Bulletin. 2019; 6(3): e87413.

40. Assari S, Caldwell CH. High Risk of Depression in High-Income African American Boys. J Racial Ethn Health Disparities. 2018; 5(4): 808-819.

41. Assari S, Lapeyrouse LM, Neighbors HW. Income and Self-Rated Mental Health: Diminished Returns for High Income Black Americans. Behav Sci (Basel). 2018; 8(5).

42. Assari S, Thomas A, Caldwell CH, et al. Blacks' Diminished Health Return of Family Structure and Socioeconomic Status; 15 Years of Follow-up of a National Urban Sample of Youth. J Urban Health. 2018; 95(1): 21-35

43. Assari S. Socioeconomic Determinants of Systolic Blood Pressure; Minorities' Diminished Returns. Journal of Health Economics and Development. 2019; 1(1): 1-11.

44. Assari S, Caldwell CH. Family Income at Birth and Risk of Attention Deficit Hyperactivity Disorder at Age 15: Racial Differences. Children (Basel). 2019; 6(1).

45. Assari S CH, Bazargan M. High Education Level Protects European Americans But Not African Americans Against Chronic Obstructive Pulmonary Disease: National Health Interview Survey, . International Journal of Biomedical Engineering and Clinical Science 2019; 5(2): 23-30. 
46. Assari S, Bazargan M. Educational Attainment Better Reduces Disability for Non-Hispanic than Hispanic Americans. European Journal of Investigation in Health, Psychology and Education. 2019; 10(1): 10-17.

47. Portugal C, Cruz TB, Espinoza L, et al. Countering tobacco industry sponsorship of Hispanic/Latino organizations through policy adoption: a case study. Health Promot Pract. 2004; 5(3 Suppl): 143S-156S.

48. Spivey JD, Lee JGL, Smallwood SW. Tobacco Policies and Alcohol Sponsorship at Lesbian, Gay, Bisexual, and Transgender Pride Festivals: Time for Intervention. Am J Public Health. 2018; 108(2): 187-188.
49. Stevens P, Carlson LM, Hinman JM. An analysis of tobacco industry marketing to lesbian, gay, bisexual, and transgender (LGBT) populations: strategies for mainstream tobacco control and prevention. Health Promot Pract. 2004; 5(3 Suppl): 129S-134S.

50. Soneji S, Knutzen KE, Tan ASL, et al. Online tobacco marketing among US adolescent sexual, gender, racial, and ethnic minorities. Addict Behav. 2019; 95: 189-196.

51. Assari S, Caldwell CH, Mincy R. Family Socioeconomic Status at Birth and Youth Impulsivity at Age 15 Blacks' Diminished Return. Children (Basel). 2018; 5(5).

52. Assari S. Socioeconomic Status and Self-Rated Oral Health; Diminished Return among Hispanic Whites. Dent J (Basel). 2018; 6(2). 